\title{
Controle social: uma análise entre percepção e prática
}

Social control: an analysis between perception and practice

\author{
Ruth Carvalho de Santana Pinho ${ }^{1}$ \\ Taianny Sterphanny Lima do Vale ${ }^{2}$
}

\section{RESUMO}

O Controle Social é essencial para legitimar a gestão pública, uma vez que o cidadão acompanha e fiscaliza as ações do governo, no entanto, o indivíduo esbarra em questões que impedem o pleno exercício da participação social. Nesse contexto, constitui objetivo principal deste estudo avaliar a relação entre a percepção e a prática do Controle Social. Para tanto, foi feita uma pesquisa quantitativa envolvendo 307 alunos do curso de Ciências Contábeis da Universidade Federal do Ceará. O instrumento de coleta utilizado foi o questionário. Adicionalmente, utilizou-se o teste de Correlação de Spearman para encontrar a relação entre as variáveis. Os resultados obtidos possibilitaram constatar a correlação positiva entre percepção e prática; o semestre e o lugar que trabalha são fatores relacionados com a prática do Controle Social, e a falta de ações promovedoras do Controle Social foi apontada como a principal barreira ao exercício da participação cidadã. Concluiu-se que a prática do Controle Social está associada à importância atribuída ao direito, porém o nível de engajamento do cidadão ainda é muito baixo, já que o indivíduo esbarra em questões culturais, sociais e políticas.

Palavras-Chave: Controle Social. Percepção. Prática.

1 Contadora, mestre em Controladoria pela Universidade de São Paulo. Doutora em Educação pela Universidade Federal do Ceará. Coordenadora do Curso de Especialização em Auditoria da Universidade Federal do Ceará, professora do Mestrado Profissional em Administração e Controladoria da Universidade Federal do Ceará. E-mail: rcspinho@ufc.br

2 Graduada em Ciências Contábeis pela Universidade Federal do Ceará. E-mail: taiannysterphanny@ hotmail.com 


\section{ABSTRACT}

Social control is essential to legitimize public management, since the citizen accompanies and supervises the actions of the government, however the individual comes up against issues that prevent the full exercise of social participation. In this context, it is the main objective of the study to evaluate the relationship between the perception and the practice of social control. For that, an quantitative research was performed with 307 students of Accounting Sciences of the Federal University of Ceará. In addition, the Spearman Correlation test was used to find the relationship between the variables. The results obtained allowed to verify the positive correlation between perception and practice, the semester and the place that works was factors related to the practice of social control, and the lack of actions promoting social control was pointed out as the main barrier to the exercise of citizen participation. It was concluded that the practice of social control is associated with the importance attributed to the law, but the level of citizen engagement is still very low, since the individual comes up against cultural, social and political issues.

Keywords: Social Control. Perception. Practice.

Recebido: 07-08-2020

Aprovado: 07-10-2020

\section{INTRODUÇÃO}

Nas últimas décadas, a palavra corrupção fez-se cada vez mais presente na sociedade brasileira. Inúmeros são os casos de fraudes, má utilização dos recursos públicos, endividamento dos entes da Federação, insatisfação popular com os serviços básicos oferecidos à população e elevada carga tributária, existindo, com isso, uma necessidade crescente de transparência e de fiscalização das contas públicas (COELHO; CRUZ; PLATT NETO, 2011). Nesse contexto, surgiram os órgãos de fiscalização 
e as leis, tais como a Lei de Responsabilidade Fiscal e a Lei de Acesso à Informação, que visam dar publicidade e transparência aos atos de governo, assim como o Controle Social tornou-se essencial para assegurar uma gestão eficiente.

O Controle Social é a ligação que existe entre Estado e sociedade. É um direito pelo qual o cidadão poderá acompanhar, fiscalizar, coletar informações, consultar, denunciar atos que estão contra o interesse público, além de outras ações que visam a avaliar o desempenho da administração pública (SERRA; CARNEIRO, 2012). Diante disso, o cidadão é a parte legítima para o exercício do Controle Social.

Estudos recentes atestam que a população atribui elevado grau de relevância à atuação cidadã na gestão da coisa pública (ARRAIS, 2016; SILVA, 2015). No entanto, apenas a percepção sobre a importância do Controle Social não garante a legitimidade da gestão, já que a eficácia do Controle Social só será garantida pela efetiva participação da população no controle sobre os atos de governo, ou seja, a efetiva prática do Controle Social (OLIVEIRA; PISA, 2015). O indivíduo deve não somente reconhecer a necessidade do Controle Social, mas deve, principalmente, praticá-lo.

Desse modo, é possível que mesmo que se reconheça a importância da participação do cidadão no contexto político brasileiro, não haja, de fato, o engajamento da população como agente fiscalizadora das ações do governo.

Nesse contexto, a pesquisa procurou responder ao seguinte questionamento: qual a relação existente entre a percepção e a efetiva prática do Controle Social? Constitui, portanto, objetivo principal do estudo analisar a relação entre a percepção e a prática do Controle Social dos alunos de Ciências Contábeis Universidade Federal do Ceará (UFC).

Alinhados ao objetivo principal, formularam-se os seguintes objetivos específicos: a) identificar o principal motivo que dificulta a prática do Controle Social; b) relacionar aspectos socioeconômicos à prática do Controle Social. 
A relevância do estudo consiste na própria legitimidade do Controle Social, haja vista ser o cidadão o agente que tem o direito e o dever de fiscalizar os atos dos governantes. Estudos atuais ratificam a necessidade do Controle Social (ARRUDA; TELES, 2010; COELHO, CRUZ; PLATT NETO, 2011; ROSA et al., 2016; SERRA; CARNEIRO, 2012), porém, existem poucas pesquisas que associem percepção à prática. Visto isso, o presente estudo aborda o Controle Social tanto no âmbito teórico quanto no âmbito prático, analisando como os discentes de contabilidade da UFC portam-se frente ao exercício do direito à informação e, principalmente, se fazem uso desse direito em prol do interesse público, já que esses são os futuros profissionais que estarão em contato direto ou indireto com a matéria governamental, e a participação cidadã deve incorporar-se ao exercício profissional e pessoal.

É importante destacar que a pesquisa compreende vários pontos referentes ao Controle Social: atribuição de importância, exercício, fatores socioeconômicos relacionados e motivos que dificultam a prática do mesmo, utilizando-se de técnicas estatísticas para comprovar os resultados do estudo.

Deve-se ressaltar que, ao restringir a pesquisa a alunos universitários, o estudo abordará o Controle Social com um público-alvo que é dotado de escolaridade e informação, sendo estes agentes importantes no processo político brasileiro.

Espera-se, ainda, que o estudo possa servir de fomento à participação social, uma vez que o trabalho será realizado diretamente com os alunos, inclusive sendo, para alguns, o primeiro contato com o tema. Além disso, espera-se trazer reflexão aos que, mesmo julgando o Controle Social importante, não o praticam. A pesquisa justifica-se, ainda, pela possibilidade de servir como base para futuros estudos sobre o assunto.

O artigo está estruturado da seguinte forma: além desta Introdução, na seção 2 é abordado o Controle Social, discorrendo sobre a importân- 
cia e os meios efetivos para exercício deste Controle; na seção seguinte, apresentam-se os procedimentos metodológicos utilizados; a seção 4 traz a análise dos dados; e, na seção 5, apresenta-se a Conclusão.

\section{FUNDAMENTAÇÃO TEÓRICA}

Esta seção visa a abordar o conceito de Controle Social que deu suporte para a elaboração do trabalho.

\subsection{IMPORTÂNCIA DO CONTROLE SOCIAL}

A Constituição Federal de 1988 introduziu no Brasil um processo democrático no qual a participação social é um direito previsto, seja por meio da obrigatoriedade de publicidade dos atos públicos ou por meio da implementação do direito à participação social. Dessa forma, o país deixou de ter um governo autoritário e repressor e passou a existir uma sociedade em que o cidadão tem o direito previsto em lei de exercer controle sobre os atos de governo.

A condição preexistente para se ter um Estado Democrático é o Controle Social, que nasce com a participação social, sendo uma característica fundamental para pôr fim à política autoritária vigente no Brasil até a promulgação da Constituição Federal do Brasil de 1988 (ARRUDA; TELES, 2010; SERRA; CARNEIRO, 2012).

O Controle Social é essencialmente democrático e decorre dos conceitos de transparência e participação popular (CONTROLADORIA GERAL DA UNIÃO, 2012). Para Pires (2011), a participação social visa a pressionar as instituições a serem mais ágeis e transparentes e proporcionam um suporte de legitimidade às decisões de direção. Trata-se de instância política da comunidade de usuários de um serviço público. A participação social é, ainda, capaz de elevar a governabilidade, garantindo a adaptabilidade das políticas públicas a longo prazo (SALLES, 2010). 
O direito do cidadão de conhecer, opinar e acompanhar as decisões governamentais, verificando a defesa dos direitos coletivos, é chamado de Controle Social (EVANGELISTA, 2010). É, ainda, o ato de confirmar, reformar e anular os atos públicos (HAIGERT, 2012).

Para enfatizar o papel do cidadão na fiscalização dos atos de governo, a própria Constituição Federal de 1988, no art. 5º inciso LXXIII, garante os meios para que se possa exercer o direito:

Qualquer cidadão é parte legítima para propor ação popular que vise a anular ato lesivo ao patrimônio público ou de entidade de que o Estado participe, à moralidade administrativa, ao meio ambiente e ao patrimônio histórico e cultural, ficando o autor, salvo comprovada má-fé, isento de custas judiciais e do ônus da sucumbência. (CF, 1988).

Desse modo, pode-se perceber que o Controle Social é uma ferramenta que garante que a administração cumpra o seu propósito, que é atender ao interesse público e defender os interesses coletivos, garantindo a eficácia, eficiência e efetividade da gestão. É mais que um direito ou um dever, é um instrumento que transforma cidadãos espectadores em cidadãos participativos (SALLES, 2010).

Diante do cenário atual, em que a corrupção, os escândalos políticos e a insatisfação popular estão evidentes no processo político brasileiro, a importância do Controle Social é evidenciada de maneira a inibir essas ações irregulares e danosas à gestão pública (COELHO; CRUZ; PLATT NETO, 2011). Com a pressão constante da sociedade, o gestor tende a coibir a corrupção, porém, com a falta de controle e impunidade, o processo tende a se inverter, crescendo os atos que caracterizam desvio de dinheiro público (RAUSCH; SOARES, 2010).

Nesse sentido, Rosa et al. (2016) apontam a importância do Controle Social no combate às fraudes e à corrupção ao afirmarem que o Brasil tem aprimorado as ferramentas de acesso à informação e aumento da 
transparência para que haja maior participação social no combate à corrupção. Acrescentam, ainda, que o cidadão é o melhor fiscalizador do governo, por ser diretamente afetado pelas ações dos governantes. A atuação do cidadão é importante ferramenta inibidora de ações eivadas de irregularidades, atuação que pode ser conseguida tanto por meio de organizações fiscalizadoras quanto pelo uso da internet.

Diante desse cenário, é notório o papel do Controle Social no combate à corrupção, na construção de um Estado democrático, no melhor desempenho da administração pública e na eficácia e eficiência da gestão.

\subsection{LRF E LAI COMO INSTRUMENTO DE FOMENTO AO CONTROLE SOCIAL}

Pode-se dizer que o Brasil tem avançado no que concerne a leis que visam dar suporte e garantir o direito da sociedade ao exercício do Controle Social, seja por meio do dever à publicidade ou por meio da obrigatoriedade da prestação de contas.

A Lei de Acesso à Informação (LAI), n ${ }^{\circ}$ 12.527, publicada em 18 de novembro de 2011, que entrou em vigor somente em 16 de maio de 2012, regulamentou o acesso do cidadão às informações produzidas e mantidas pelos órgãos e entidades públicas, dando publicidade a estas, possibilitando uma administração mais transparente e facilitando a participação social.

Rosa et al. (2016) afirmam que, com a LAI, espera-se que o cidadão tenha uma participação mais efetiva no controle aos atos de governo, inclusive inibindo a corrupção. Acrescentam também as principais características trazidas pela lei que contribui para o exercício do Controle Social, tais como a observância do princípio da publicidade, a divulgação de informações de interesse público e o desenvolvimento do Controle Social.

Convergindo com o pensamento de Rosa et al. (2016), Bernardes, Santo e Rover (2010) afirmam que a LAI é um instrumento fundamental para garantir a efetiva participação dos cidadãos na gestão pública, uma 
vez que essa dispõe de prazos e procedimentos a serem observados pelos órgãos públicos na defesa dos direitos à informação, sendo a publicidade o princípio fundamental norteador dos atos do governo.

A LAI impôs aos governantes a obrigatoriedade da divulgação de informações. Sendo assim, promove a transparência, facilitando que a sociedade participe de forma mais ativa na gestão. Conforme o artigo $8^{\circ}$ da LAI, é dever dos órgãos e entidades públicas promover, independentemente de requerimentos, a divulgação em local de fácil acesso, no âmbito de suas competências, de informações de interesse coletivo ou geral por eles produzidas ou custodiadas.

Outra lei que vem corroborar o exercício do Controle Social, garantido pela publicidade e prestação de contas à população, é a Lei de Responsabilidade Fiscal, conhecida como LRF, publicada em 5 de maio de 2000. A Lei de Responsabilidade Fiscal é uma ferramenta que veio dar suporte aos gestores para adequada administração dos recursos públicos, uma vez que é composta por regras que devem ser cumpridas tanto pela administração pública direta quanto indireta. Além disso, a LRF é um mecanismo de Controle Social, já que busca a transparência, prestação de contas e publicidade das contas públicas. Os cidadãos, tendo acesso às contas do governo, poderão exercer de forma mais intensa o Controle Social.

Medeiros et al. (2016, p. 1), por sua vez, afirmam que

reflete um conjunto de normas sobre finanças públicas voltadas para a responsabilidade na gestão fiscal, que está amparada nos pilares de planejamento, transparência, controle e responsabilização no uso dos recursos públicos.

A transparência e a publicidade das contas de governo são, portanto, preceitos que estão contemplados e assegurados tanto pela LRF quando pela LAI, porém, um dos grandes desafios para a efetividade da participação popular é a qualidade da informação. Nesse sentido, há a necessidade de um modelo que avalie a transparência das contas públicas, visando ao 
aperfeiçoamento da informação e, consequentemente, favoreça o exercício do Controle Social.

\subsection{MEIOS PARA O EXERCÍCIO DO CONTROLE SOCIAL}

Como dito anteriormente, o Brasil já vem avançando em relação aos meios que facilitem e incentivem a prática do Controle Social. A Constituição de 1988, a Lei de Acesso à Informação, a Lei de Responsabilidade Fiscal, a Lei 8.666/67 (conhecida por Lei das Licitações), os órgãos como a Controladoria Geral da União, entre outros, podem ser considerados mecanismos que preveem a participação do cidadão.

Um dos canais diretos de prestação de contas à população é o Portal de Transparência, cuja obrigatoriedade foi introduzida pela Lei Complementar 131/2009. O Portal de Transparência apresenta, em um único sítio, informações sobre aplicação dos recursos federais, estaduais e municipais, inclusive informações sobre as execuções orçamentária e financeira (CONTROLADORIA GERAL DA UNIÃO, 2017). O acesso do cidadão ao Portal de Transparência implica a conscientização da população sobre cidadania e leva ao crescimento da nação (MARTINS; VÉSPOLI, 2013).

Outra forma de participação popular são as audiências públicas, instrumentos que os órgãos públicos podem dispor para promover um diálogo com a sociedade em geral para solução de questões de interesse público. Tal ação é fundamental para solução de um conflito social, uma vez que todos os atores sociais envolvidos no problema têm participação nas discussões, transformando uma democracia representativa em participativa (CÉSAR, 2011).

Vale ressaltar que a realização de audiências públicas está prevista em várias leis, dentre estas a Constituição Federal de 1988 e a Lei 8666/93. A Lei das Licitações no art. 39 prevê a obrigatoriedade da realização de audiências públicas no início do processo licitatório quando o valor estimado para licitação ou para um conjunto de licitações sucessivas ou si- 
multâneas ultrapasse o valor de R \$ 150.000.000,00. Por sua vez, compete ao Congresso Nacional e às suas Casas realizarem audiências públicas com a sociedade civil (BRASIL, 1988).

As ouvidorias, por sua vez, são canais de comunicação entre a sociedade e o poder público, em que o cidadão pode prestar queixa sobre os serviços públicos ou requerer informações de interesse individual ou coletivo. Nesse sentido, Romero e Sant'Anna (2014) afirmam que ouvidorias públicas vêm se destacando como instrumento de relacionamento da população com os diversos órgãos e entidades da administração pública, uma vez que o cidadão tem o direito à informação e a administração pública tem o dever de facilitar e garantir o acesso.

Outra ferramenta de participação popular que permite o fomento do Controle Social são os Conselhos Gestores de Políticas Públicas. Sobre os Conselhos Gestores, Gomes (2015, p. 4) afirma:

Dessa forma, no que tange à eficiência das políticas públicas, podemos identificar dois objetivos principais dos conselhos gestores de políticas públicas: a identificação, captação e ponderação constante das preferências da sociedade, com vistas à formulação de políticas públicas e o controle social sobre estas, incluindo a responsividade às demandas da sociedade e a responsabilização dos governantes.

Os Conselhos gestores de políticas públicas são canais efetivos de participação, que permitem que o exercício da cidadania seja uma realidade e que fortalece a participação democrática da população. Existem Conselhos Gestores de Políticas Públicos voltados para diversas áreas, tais como: Conselho Municipal de Saúde, Conselho de Alimentação Escolar, Conselho de Controle Social do Bolsa Família, entre outros (CONTROLADORIA GERAL DA UNIÃO, 2017). Dessa forma, ainda de acordo com a Controladoria Geral da União (2017), é notório que tal mecanismo é fundamental para prestação de contas à população dos atos do Governo. O cidadão ainda pode dispor de órgãos que dão suporte ao exercício 
da cidadania, apurando irregularidades, como preceitua a Controladoria Geral da União (2012, p. 25):

O cidadão, no exercício do Controle Social, deve estar atento ao
cumprimento dos objetivos das políticas públicas, denuncian-
do possíveis irregularidades encontradas aos diversos órgãos
que possuem competência para atuar. Conforme o caso, podem
ser contatados órgãos como a Controladoria-Geral da União
(CGU), o Ministério Público Estadual, o Ministério Público
Federal, os Tribunais de Contas do Município, do Estado e da
União; as Câmaras de Vereadores e Assembleias Legislativas; e
os Conselhos responsáveis pelo acompanhamento da respectiva
política.

Assim, existem vários meios que permitem o indivíduo exercer o Controle Social. Logo, a participação social é assegurada por lei, qualificando o cidadão para o exercício do Controle Social.

\subsection{EFETIVO EXERCÍCIO DO CONTROLE SOCIAL E SUAS BARREIRAS}

Percebe-se que existe um consenso na literatura quanto à importância do Controle Social para inibir fraudes e corrupção, para garantir que a administração pública cumpra seu papel tendo como escopo o interesse coletivo, além de garantir uma gestão eficiente, eficaz e legítima. Para que o Controle Social atenda aos objetivos que lhe foram propostos, tem que existir um efetivo exercício do direito.

Oliveira e Pisa (2015) concluíram que a efetividade das ações governamentais só será possível quando a sociedade assumir plenamente o exercício da cidadania, e essa só será alcançada com a maior participação social e o estímulo ao efetivo exercício do Controle Social pela população.

Silva, Cançado e Santos (2016) afirmam que o sistema republicano brasileiro ficará limitado enquanto não existir entendimento sobre os mecanismos de Controle Social. A população deve compreender como 
utilizar as práticas de controle para aprimorar o conceito de democracia.

De acordo com a Carta Magna de 1988, cidadão é aquele indivíduo a quem esta confere direitos e garantias individuais, políticos, sociais, econômicos e culturais, e lhe dá o poder de seu efetivo exercício, além de meios processuais eficientes contra a violação de seu gozo ou fruição por parte do Poder Público. Por conseguinte, o desenvolvimento do Controle Social está intimamente ligado com o desenvolvimento cultural do povo brasileiro, cuja educação contribui para se ter uma sociedade participativa quanto aos interesses coletivos e não somente quanto aos interesses individuais.

Dessa forma, é notório que a participação cívica é fundamental para o aprimoramento dos conceitos de democracia, república e cidadania, porém, um dos maiores desafios para a concretização do Controle Social é justamente o exercício dessa fiscalização e acompanhamento dos atos de governo, já que o cidadão esbarra em questões culturais e até mesmo no desconhecimento do direito que inibe a efetiva prática do controle.

Sobre o cenário brasileiro, no que consiste ao efetivo Controle Social, Arruda e Teles (2010, p. 35) afirmam:

A bem da verdade, é fato que o Controle Social vem avançando de forma lenta e gradativa, motivo pelo qual ainda é algo de difícil concretização, pois esbarra num problema cultural na medida em que de um lado se encontram vários administradores públicos que preferem manter a população na ignorância quanto a seus atos, e de outro, a sociedade que mesmo dispondo de meios apropriados não consegue exercer a contento o Controle Social no sentido de fiscalizar e cobrar resultados, tendo em vista a ausência de tradição e a frágil consciência política resultantes da carência histórica de transparência que viveu o país.

Outro fator que vem a dificultar o exercício do Controle Social é a falta de clareza das informações divulgadas pela Administração Pública, uma vez que nem a parte mais escolarizada da população tem conhecimento suficiente para entender o funcionamento dos instrumentos de 
Controle Social. Somado a tal situação, percebe-se ainda que as ações governamentais são precárias no fomento à participação social, visto que não há ações com extensão suficiente para motivar e educar a população no que concerne à participação cidadã (ARRUDA; TELES, 2010; DI PIETRO, 2015).

Ainda sobre o assunto, Bicalho (2013) defende que a prestação de contas seja feita de forma mais compreensiva e de fácil avaliação. Acrescenta, ainda, que o exercício do Controle Social é desafiador, já que requer a ruptura de um sistema burocrático que privilegia as questões mais técnicas. Do exposto, nota-se que o Controle Social não é algo fácil de concretizar, uma vez que os mecanismos de controle não são acessíveis a parte da população simplesmente porque lhes falta o domínio técnico da informação.

Para reforçar a ideia, Sabioni et al. (2016, p. 492) desenvolveram um trabalho em que buscavam compreender e identificar quais aspectos são mais relevantes para o engajamento da população no Controle Social. Para tanto, utilizou como público-alvo da sua pesquisa os municípios de Minas Gerais. Como resultado da pesquisa, tem-se os seguintes dados:

\footnotetext{
Depreende-se que uma parcela consideravelmente grande $(75 \%$ do total ou 640 municípios mineiros) apresenta níveis de potencial para atuação cidadã abaixo de 53,39\%. Apenas 30,51\% dos municípios do grupo 4, de maior potencial de atuação, apresentam valores acima de $65 \%$, isto é, somente $7,62 \%$ dos municípios do estado possuem níveis superiores a $65 \%$
}

Sobre a pesquisa, pode-se perceber que ainda existe um grande desafio para que haja uma efetiva prática do Controle Social, pois o engajamento do cidadão ainda não é exercido de forma a maximizar a sua excelência, para que este possa realmente cumprir o papel que exerce sobre os atos do governo, desde a inibição de ações detentoras de irregularidade até um desempenho mais eficiente.

Figueiredo e Santos (2013) enfatizam que o processo de conscientização da sociedade como cidadão ativo, que utiliza as ferramentas de 
Controle Social, é longo. Os diversos segmentos sociais precisam ser atingidos para que se tenha uma sociedade participativa, na qual as escolas e as universidades brasileiras têm papel fundamental de formação quanto aos conceitos de transparência, publicidade e papel de incentivo ao Controle Social.

Nesse contexto, destaca-se o educador. Para enfatizar o papel do professor e da escola como agentes decisivos no processo de formação, Gadotti (2012, p. 2) afirma:

\footnotetext{
Por isso, uma perspectiva emancipatória da educação e do trabalho deve desenvolver a capacidade de pensar criticamente a realidade e promover a justiça e a solidariedade, fundada na ética, e respeitando a dignidade e a autonomia do educando. Daí a importância estratégica do professor como intelectual transformador e a escola como um espaço de contestação e de construção de uma visão crítica da sociedade, formando para o exercício da cidadania desde a infância.
}

Depreende-se que o Controle social é antes de tudo, a possibilidade de estabelecer a equidade entre os diferentes grupos de interesse da sociedade. Trata-se de um tema abrangente e os limites desse estudo foram estabelecidos na Metodologia apresentada na próxima seção.

\section{METODOLOGIA DA PESQUISA}

Com o objetivo principal de avaliar a relação existente entre a percepção acerca do Controle Social e o efetivo exercício do direito, foi adotado como público-alvo da pesquisa os alunos de Contabilidade da Universidade Federal do Ceará efetivamente matriculados no Curso.

Primeiramente, foram escolhidos alunos universitários como público-alvo da pesquisa por serem indivíduos que se pressupõe ter maior nível de escolaridade, contribuindo, assim, para ter um maior acesso à informação e ao conhecimento político. Posteriormente, a escolha de a 
pesquisa ser realizada com alunos de Ciências Contábeis especificamente foi pautada no fato de a matriz curricular conter disciplinas com conteúdo da área de gestão governamental.

O critério utilizado para seleção da instituição de ensino foi o Ranking Universitário da Folha de São Paulo. Referido ranking foi escolhido por analisar as instituições de ensino em 6 categorias: avaliação do mercado; qualidade de ensino; doutorado e mestrado; Enade; professores com dedicação integral e parcial e avaliadores do MEC. Foram analisados os anos 2014, 2015 e 2016. Observados os critérios descritos, a instituição de ensino mais bem posicionada em relação ao Curso de Ciências Contábeis no estado do Ceará foi a Universidade Federal do Ceará (UFC).

Quanto aos objetivos, a pesquisa é descritiva, já que, segundo Gil (2010), o foco principal é fazer relação entre variáveis, utilizando-se de técnicas padronizadas de coletas de dados. Ainda com base em Gil (2010), o presente estudo, quanto aos procedimentos técnicos, classifica-se como bibliográfico e levantamento, pois se utilizou de estudos anteriores, como livros e artigos, para elaboração. Além disso, a pesquisa envolve o contato com o público-alvo que se deseja conhecer, no caso, por meio de questionários aplicados aos alunos de Ciências Contábeis da UFC. Por fim, quanto à abordagem do problema, classifica-se como quantitativa, já que se utilizam técnicas estatísticas para medir o grau de relação entre a percepção acerca do Controle Social e a prática deste (KAUARK; MANHÃES; MEDEIROS, 2010).

Para alcançar o objetivo do estudo, foi aplicado um questionário a 307 alunos de Ciências Contábeis da UFC. O total de alunos ativos no curso é composto por 430 discentes no período diurno e 399 discentes no período noturno, totalizando 829 alunos. A técnica de amostragem utilizada foi do tipo não probabilístico por acessibilidade ou por conveniência, mas que assegura uma confiança de 95\% e uma margem de erro de 5\% da população total. Nenhum questionário foi invalidado, por atenderem a todos os requisitos necessários. Assim, a amostra final foi de 307 alunos 
matriculados, que consiste em $37,03 \%$ do universo da pesquisa.

O questionário foi estruturado com base no Referencial Téorico, utilizando a escala de Likert. Sobre a escala de Likert, Silva Junior e Costa (2014) afirmam que consiste em tomar um construto e desenvolver um conjunto de afirmações relacionadas à sua definição, para as quais os respondentes emitirão seu grau de concordância.

O questionário apresenta quatro partes: os dados socioeconômicos do respondente, a percepção acerca do Controle Social, a aplicação do Controle Social e os motivos que dificultam a prática do controle. No tocante aos dados socioeconômicos, foram observados os seguintes itens: renda familiar, semestre cursado, escolaridade dos pais, lugar em que trabalha.

Em relação à percepção, os alunos atribuíram grau de concordância a respeito de assertivas que versavam sobre o Controle Social. Foi definida uma escala de 1 a 5 , sendo 1 para concordância extremamente fraca e 6 para concordância extremamente forte. As assertivas foram elaboradas a partir do referencial teórico apresentada no presente estudo. O Quadro 1 apresenta as perguntas dessa parte do questionário.

Quadro 1: Percepção do Controle social

\begin{tabular}{|c|c|c|c|c|c|c|}
\hline Questões & 1 & 2 & 3 & 4 & 5 & 6 \\
\hline Tenho conhecimento acerca do conceito de Controle Social. & & & & & & \\
\hline $\begin{array}{l}\text { Para que as ações realizadas pelos governantes estejam alinhadas ao inte- } \\
\text { resse público é necessário que os cidadãos atuem como fiscalizadores das } \\
\text { contas do Governo }\end{array}$ & & & & & & \\
\hline $\begin{array}{l}\text { A participação popular no controle das contas do Governo é essencial à } \\
\text { diminuição da corrupção. }\end{array}$ & & & & & & \\
\hline $\begin{array}{l}\text { É necessário que o governo preste contas à população dos gastos e das } \\
\text { ações desenvolvidas pelos políticos e administradores. }\end{array}$ & & & & & & \\
\hline
\end{tabular}

Fonte: Elaborado pelas autoras (2017).

Para adentrar à efetiva aplicação do Controle Social, foram feitos alguns questionamentos sobre ações que correspondem ao exercício do 
Controle Social, extraídas do Portal de Transparência. As respostas foram estruturadas também na escala de Likert a respeito da frequência com que o respondente praticava tal ação, variando de "Nunca" até "Sempre". Necessário se fazia saber até que ponto o conhecimento sobre controle social se concretizava na experiência pessoal de cada estudante. O Quadro 2 apresenta as perguntas que foram aplicadas.

Quadro 2: Efetivo exercício do Controle Social

\begin{tabular}{|l|l|l|l|l|l|}
\hline \multicolumn{1}{|c|}{ Questões } & Nunca & Raramente & Às vezes & Frequentemente & Sempre \\
\hline $\begin{array}{l}\text { Acessa o Portal de Transparên- } \\
\text { cia para acompanhar as ações do } \\
\text { governo? }\end{array}$ & & & & & \\
\hline $\begin{array}{l}\text { Participa de algum curso (pode } \\
\text { ser palestra, aulas ou qualquer } \\
\text { outra de conhecimento) sobre } \\
\text { controle social? }\end{array}$ & & & & & \\
\hline $\begin{array}{l}\text { Já fez alguma denúncia sobre ir- } \\
\text { regulares (pode ser de servidores } \\
\text { públicos, órgãos públicos ou de } \\
\text { recurso público)? }\end{array}$ & & & & & \\
\hline $\begin{array}{l}\text { Acompanha alguma licitação } \\
\text { pública e denunciou irregulares, } \\
\text { caso as tenha detectado? }\end{array}$ & & & & & \\
\hline $\begin{array}{l}\text { Frequenta alguma reunião pro- } \\
\text { movida por Conselhos Munici- } \\
\text { pais? }\end{array}$ & & & & & \\
\hline $\begin{array}{l}\text { Solicita alguma informação de } \\
\text { interesse público frente aos ór- } \\
\text { gãos do governo? }\end{array}$ & & & & & \\
\hline
\end{tabular}

Fonte: Elaborado pelas autoras (2017).

Ao final dessa parte foi perguntado qual era a principal razão para o não exercício desse direito, dando as seguintes opções: falta de interesse sobre a matéria pública; falta de conhecimento sobre os meus direitos como cidadão; falta de divulgação do governo sobre ações fomentadores do controle; outro motivo (especificar).

Para análise foram realizados os testes Kolmogorov-Smirnov para verificar a normalidade dos dados; diferença de médias não-paramétricas de 
Kruskall-Wallis para relacionar aspectos socioeconômicos à prática do Controle Social; teste de correlação de Spearman para avaliar a relação entre prática e percepção do Controle Social. Os testes estatísticos mencionados foram realizados no Statistical Package for the Social Sciences (SPSS), versão 22.

\section{ANÁLISE DOS RESULTADOS}

Esta seção apresenta os dados levantados pela pesquisa, bem como os resultados obtidos pela análise embasada na estatística descritiva e na estatística inferencial, abrangendo os testes citados na seção que trata da metodologia.

\subsection{ANÁLISE DESCRITIVA}

A primeira parte do questionário visava a traçar um perfil socioeconômico dos respondentes, conforme observa-se na Tabela 1 .

Tabela 1: Características socioeconômicas

\begin{tabular}{|c|c|c|}
\hline & Quantidade de alunos & Porcentagem \\
\hline \multicolumn{3}{|l|}{ Semestre } \\
\hline 1 a 3 & 108 & $35,18 \%$ \\
\hline 4 a 6 & 95 & $30,94 \%$ \\
\hline 7 a 9 & 104 & $33,88 \%$ \\
\hline \multicolumn{3}{|l|}{ Renda } \\
\hline Até 937 & 19 & $6,19 \%$ \\
\hline 937,01 a 2811 & 109 & $35,30 \%$ \\
\hline 2811,01 a 4685 & 81 & $26,38 \%$ \\
\hline Acima de 4685 & 98 & $31,92 \%$ \\
\hline \multicolumn{3}{|l|}{ Lugar onde trabalha } \\
\hline Instituição Privada & 111 & $36,16 \%$ \\
\hline Instituição Pública & 57 & $18,57 \%$ \\
\hline Não & 139 & $45,28 \%$ \\
\hline \multicolumn{3}{|l|}{ Escolaridade dos pais } \\
\hline Fundamental & 52 & $16,94 \%$ \\
\hline
\end{tabular}


Tabela 1: Características socioeconômicas (continuação)

\begin{tabular}{c|c|c}
\hline Médio & 142 & $46,25 \%$ \\
\hline Superior & 113 & $36,81 \%$ \\
\hline
\end{tabular}

Fonte: Dados da Pesquisa (2017).

Em relação ao semestre, 108 alunos $(35,18 \%)$ cursam do $1^{\circ}$ ao $3^{\circ}$ semestre, enquanto $95(30,94 \%)$ cursam do $4^{\circ}$ ao $6^{\circ}$, seguidos por 104 $(33,88 \%)$ do $7^{\circ}$ a $9^{\circ}$ semestre. Pode-se perceber que a maior parte dos respondentes cursa os semestres iniciais, porém a amostra foi distribuída de forma semelhante entre os três grupos.

A renda foi dividida em quatro grupos: até 937; de 937,01 a 2811; de 2811,01 a 4685; e acima de 4685,01. A maior parte dos alunos (35,30\%) enquadra-se na segunda faixa de nível de renda, enquanto a menor quantidade de alunos encontra-se inseridos na primeira faixa de nível de renda, apenas $6,19 \%$.

No que tange ao lugar em que trabalha, a amostra se comportou da seguinte forma: 111 alunos trabalham em Instituição Privada, 57 alunos trabalham em Instituição Pública e 139 alunos não trabalham. Com base nos dados, pode-se perceber que o maior número de respondentes $(45,28 \%)$ não trabalha.

O último critério socioeconômico a ser analisado foi o nível de escolaridade dos pais (fundamental médio, superior), sendo composto por $16,94 \%$ com nível fundamental, 46,25\% nível médio e 36,81\% nível superior.

\subsubsection{PERCEPÇÕES SOBRE O CONTROLE SOCIAL}

Em relação à análise descritiva, foram observadas as características do tópico do questionário relacionado à percepção, bem como do tópico relacionado à aplicação. Em relação à percepção, foram feitas quatro afirmativas sobre a importância do Controle Social. O respondente deveria atribuir valores de 1 a 6 a cada afirmação, sendo 1- concordância 
extremamente fraca, 2- concordância muito fraca, 3- concordância fraca, 4- concordância forte, 5- concordância muito forte e 6- concordância extremamente forte.

A primeira afirmação versava sobre o conhecimento satisfatório dos alunos sobre o conceito de Controle Social, em média, os mesmos atribuíram grau de concordância de 2,80. Assim, pode-se atribuir uma concordância muito fraca ou fraca. A assertiva seguinte considerava necessária a atuação cidadã para que as ações dos governantes estivessem alinhadas ao interesse público, obtendo uma média na escala de Likert de 5,12, um valor entre concordância muito forte ou extremamente forte.

As duas últimas afirmações consideravam o papel da participação popular no controle à corrupção e a necessidade de prestação de contas, respectivamente. Obtiveram-se as médias de 5,30 e 5,66. Dessa forma, com base no que foi respondido pelos alunos de Ciências Contábeis da UFC, pode-se extrair que a média geral da percepção foi $4,71, \operatorname{logo}$, os respondentes, em média, concordam fortemente ou concordam muito fortemente com as afirmações sobre a importância do Controle Social.

Tabela 2: Afirmações sobre o Controle Social

\begin{tabular}{c|c}
\hline Afirmação sobre percepção & Média por pergunta \\
\hline Conhecimento satisfatório sobre Controle Social & 2.80 \\
\hline Alinhar ações do governo ao interesse público & 5,12 \\
\hline Inibição da corrupção & 5,30 \\
\hline Necessidade de prestação de contas & 5,66 \\
\hline Geral & 4,71 \\
\hline
\end{tabular}

Fonte: Dados da Pesquisa (2017).

Ao considerar a percepção referente a cada item, a maior média foi atribuída à afirmação necessidade de prestação de contas $(5,66)$ e a menor média foi atribuída ao conhecimento acerca do Controle Social $(2,80)$. Esse percentual se sobressai, principalmente, porque se trata de um público, em tese, bem-informado, diferente do cidadão comum, seja pelo 
nível universitário, seja pelo curso que realizam com significativa carga de estudos sobre a temática.

Tabela 3: Média de percepção por aluno

\begin{tabular}{c|c|c}
\hline Média de percepção & Quantidade de alunos & Porcentagem \\
\hline Até 2 & 3 & $0,97 \%$ \\
\hline Entre 2,1 e 3 & 10 & $3,25 \%$ \\
\hline Entre 3,1 e 4 & 33 & $10,75 \%$ \\
\hline Entre 4,1 e 5 & 165 & $53,75 \%$ \\
\hline Entre 5,1 e 6 & 96 & $31,27 \%$ \\
\hline Total & 307 & $100 \%$ \\
\hline
\end{tabular}

Fonte: Dados da Pesquisa (2017).

No que se refere a cada indivíduo da amostra, apenas 13 alunos tiveram grau de percepção até 3 , ou seja, somente $4,22 \%$ da amostra expressam uma concordância fraca a respeito da importância do Controle Social. A maior faixa de percepção foi entre 4,1 e 5, compreendendo 53,75\% dos discentes. Por fim, 95,78\% dos alunos concordaram forte, muito forte ou extremamente forte, demonstrando uma elevada percepção.

\subsubsection{PRÁTICA DO CONTROLE SOCIAL}

Para analisar a prática do Controle Social, foram elaboradas seis perguntas que correspondem ao exercício deste direito. O respondente deveria marcar o item que se referia à frequência com que realizava a ação, tendo cinco opções que variavam de "nunca" até "sempre". Para que fosse possível a análise dos dados, foram atribuídos valores a cada alternativa, sendo: 1 - Nunca, 2 - Raramente, 3 - Às vezes, 4 - Frequentemente, 5 - Sempre. 


\begin{tabular}{l|c}
\hline Perguntas & Média por pergunta \\
\hline Acessa ao Portal de Transparência? & 2,08 \\
\hline Participa de cursos sobre Controle Social? & 1,72 \\
\hline Denuncia irregularidades? & 1,51 \\
\hline Acompanha licitações públicas? & 1,44 \\
\hline Frequenta reuniões promovidas por Conselhos & 1,22 \\
Municipais? & 1,52 \\
\hline Solicita informação de interesse público? & 1,58 \\
\hline Total & \\
\hline
\end{tabular}

Fonte: Dados da pesquisa (2017).

Ao analisar a aplicação, a média dos discentes foi de 1,58, ou seja, os respondentes em geral nunca praticaram as ações citadas ou raramente as praticam. Se observada a aplicação do Controle Social em relação a cada umas das seis perguntas da Tabela 4, a maior média de respostas foi a de acesso ao Portal de Transparência $(2,08)$ e a menor média foi referente a frequentar reuniões promovidas por Conselhos Municipais $(1,22)$. Vale considerar que, em geral, todas as perguntas acerca da prática tiveram como resposta "nunca" ou "raramente".

Tabela 5: Quantidade de alunos por nível de prática

\begin{tabular}{c|c|c}
\hline Média de prática & Quantidade de alunos & Porcentagem \\
\hline Até 2 & 257 & $83,72 \%$ \\
\hline Entre 2,1 e 3 & 44 & $14,34 \%$ \\
\hline Entre 3,1 e 4 & 5 & $1,62 \%$ \\
\hline Entre 4,1 e 5 & 1 & $0,32 \%$ \\
\hline Total & 307 & $100 \%$ \\
\hline
\end{tabular}

Fonte: Dados da Pesquisa (2017).

Se avaliada a média de cada indivíduo, apenas 6 dos 307 discentes tiveram média de aplicação maior que 3, ou seja, somente 1,94 \% da amostra. Além disso, somente 1 aluno teve média de aplicação maior que 4. Por fim, a maior parte de amostra concentra-se na faixa de prática de até 2 , um total de mais de $80 \%$ dos alunos. Desse modo, pode-se perceber o baixo nível de prática das ações que correspondem ao exercício do Controle Social.

Tabela 6: Análise descritiva da percepção e da prática 


\begin{tabular}{c|c|c}
\hline ANÁLISE DESCRITIVA & PERC & APLIC \\
\hline Média & 4,7182 & 1,5809 \\
\hline Mediana & 4,75 & 1,5 \\
\hline Variância & 0,514 & 0,314 \\
\hline Desvio-padrão & 0,71715 & 0,56033 \\
\hline Mínimo & 1,00 & 1,00 \\
\hline Máximo & 6,00 & 5,00
\end{tabular}

Fonte: Dados da pesquisa (2017).

Diante dos dados apresentados, pela comparação da percepção à prática do Controle Social, pode-se atribuir que existe grande diferença entre as duas variáveis, uma vez que a média de percepção é 4,71 e a média de prática é 1,58.

\subsubsection{MOTIVOS QUE DIFICULTAM A PRÁTICA DO CONTRO- LE SOCIAL}

Ainda sobre o questionário, a última pergunta foi voltada para a principal dificuldade que os alunos encontraram para a prática do Controle Social. Tal questionamento foi feito com o propósito de atingir ao primeiro objetivo específico, que é identificar o principal motivo que dificulta a prática do Controle Social.

Tabela 7: Motivos que dificultam a prática do Controle Social

\begin{tabular}{l|c|c}
\hline Motivo & Quantidade & Porcentagem \\
\hline Falta de interesse na matéria pública & 86 & $28,01 \%$ \\
\hline Falta de conhecimentos sobre meus direitos como cidadão & 49 & $15,96 \%$ \\
\hline $\begin{array}{l}\text { Falta de divulgação do governo de ações fomentadoras do Con- } \\
\text { trole Social }\end{array}$ & 139 & $45,28 \%$ \\
\hline Outros motivos & 33 & $10,75 \%$ \\
\hline
\end{tabular}

Fonte: Dados da pesquisa (2017).

Como mostram os dados da amostra, $45,28 \%$ dos respondentes consideram a falta de ações fomentadoras do Controle Social como a principal barreira para a efetiva prática do direito. Dentre o grupo de 'outros motivos', a resposta mais recorrente foi falta de tempo (20 alunos), segui- 
das da falta de clareza das informações divulgadas, falta de confiança nas ações dos governantes, pouca motivação, medo de denunciar (1 aluno) e falta de credibilidade nas leis.

\subsection{ANÁLISE QUANTITATIVA}

Com objetivo específico de relacionar aspectos socioeconômicos trabalhados na amostra à prática do Controle Social, foi utilizado o teste de diferença de médias. Primeiramente, foi realizado o teste Kolmogorov-Smirnov que apontou a não normalidade dos dados. Assim, o teste de diferença de médias adequado foi o teste não-paramétrico de Kruskall-Wallis.

Tabela 8: Teste de Kruskall-Wallis

\begin{tabular}{c|c|c|c|c|c|c|c}
\hline Renda & $\begin{array}{c}\text { Média } \\
\text { Renda }\end{array}$ & $\begin{array}{c}\text { Escolaridade } \\
\text { dos pais }\end{array}$ & $\begin{array}{c}\text { Média } \\
\text { Escolari- } \\
\text { dade }\end{array}$ & Semestre & $\begin{array}{c}\text { Média } \\
\text { Semestre }\end{array}$ & Trabalho & $\begin{array}{c}\text { Média } \\
\text { Trabalho }\end{array}$ \\
\hline Até 937 & 1,3461 & Fundamental & 1,4987 & $1^{\circ}$ a $3^{\circ}$ & 1,3104 & $\begin{array}{c}\text { Inst. } \\
\text { Privada }\end{array}$ & 1,5621 \\
\hline $\begin{array}{c}937,01 \text { a } \\
2811\end{array}$ & 1,5922 & Médio & 1,5712 & $4^{\circ}$ a $6^{\circ}$ & 1,6804 & $\begin{array}{c}\text { Inst. } \\
\text { Pública }\end{array}$ & 1,8154 \\
\hline $\begin{array}{c}2811,01 \text { a } \\
4685\end{array}$ & 1,4568 & Superior & 1,5199 & $7^{\circ}$ a $9^{\circ}$ & 1,6502 & $\begin{array}{c}\text { Não } \\
\text { trabalho }\end{array}$ & 1,4094 \\
\hline $\begin{array}{c}\text { Acima de } \\
4685,01\end{array}$ & 1,5883 & & & & & & \\
\hline Sig. & 0,508 & \multicolumn{2}{|c|}{0,839} & & \multicolumn{2}{c|}{0,003} & \\
\hline
\end{tabular}

Fonte: Dados da pesquisa (2017).

O teste foi feito com uma confiança de $95 \%$, o que implica uma significância a 5\% $(0,05)$. Dessa forma, o critério socioeconômico que obteve significância menor que 0,05 está relacionado com a prática do Controle Social, o que obteve significância maior que 0,05 não está relacionado. Ao analisar os resultados do teste de média, pode-se perceber que dentre os critérios observados, apenas o semestre cursado (0.003) e o lugar onde trabalha $(0,013)$ estão relacionados com o exercício do Controle Social.

Os discentes que trabalham em Instituição Pública foram aqueles que 
apresentaram maior média de aplicação dos instrumentos de Controle Social $(1,81)$, enquanto a menor média foi dos alunos que não trabalham $(1,40)$, ratificando a relação entre o ambiente de trabalho com a prática do Controle Social.

Em relação ao semestre cursado, os alunos de $1^{\circ}$ a $3^{\circ}$ semestre tiveram média de prática de 1,31 , enquanto os alunos de $4^{\circ}$ a $6^{\circ}$ semestre tiveram média de 1,68 , o que pressupõe que o período cursado está ligado ao nível de prática dos instrumentos provedores do Controle Social.

Com o objetivo geral de avaliar a relação existente entre a percepção e a prática do Controle Social, foi utilizado o Teste de Correlação, que tem como função medir a intensidade de relação linear ou não linear entre duas variáveis, assim pode-se extrair a existência ou não de uma relação entre duas variáveis (LIRA, 2016). O teste de correlação adequado para a amostra, devido à não normalidade dos dados, foi o teste correlação de Spearman.

O teste de correlação de Spearman avalia a relação monotônica entre duas variáveis contínuas ou ordinais, seja ela linear ou não. Em uma relação monotônica, as variáveis tendem a mudar juntas, mas não necessariamente a uma taxa constante. $\mathrm{O}$ coeficiente baseia-se nos valores classificados de cada variável, em vez de os dados brutos. Ou seja, caso não seja observada uma relação linear entre as variáveis, o coeficiente de Spearman é uma ótima alternativa.

Tabela 9: Correlação entre percepção e prática

\begin{tabular}{l|c|c|c}
\hline & & APLIC & PERC \\
\hline \multirow{3}{*}{ APLIC } & Coeficiente de Correlação & &, $242 * *$ \\
\cline { 2 - 4 } & Sig. (2 extremidades) & &, 000 \\
\hline & $\mathrm{N}$ & & 307 \\
\hline \multirow{3}{*}{ PERC } & Coeficiente de Correlação &, $242 * *$ & \\
\hline & Sig. (2 extremidades) &, 000 & \\
\hline & $\mathrm{N}$ & 307 & \\
\hline
\end{tabular}

Fonte: Dados da pesquisa (2017).

** A correlação é significativa no nível 0,01 (2 extremidades).

Com as informações extraídas do teste estatístico, pode-se atribuir 
que a prática e a percepção do Controle Social estão correlacionadas positivamente a um nível de significância de 0,01 , já que a significância do teste foi 0,000 (menor que 0,01). Assim, depreende-se que quanto maior o nível de importância que o indivíduo atribui ao Controle Social, maior será o nível de prática do mesmo.

Outra informação importante a respeito do teste de Correlação de Spearman é que este varia de +1 até -1 , quanto mais próximos às extremidades, mais forte será a correlação entre as variáveis. Com base nos resultados do teste, aplicação e percepção do Controle Social estão correlacionados a 0,242, ou seja, fraca associação entre as variáveis.

Adicionalmente, foi verificada a correlação entre o conhecimento alegado pelos respondentes sobre o conceito de Controle Social, primeira pergunta da categoria "percepção", e cada uma das perguntas relacionadas à categoria "aplicação", bem como em relação à aplicação em geral.

Tal procedimento foi realizado com intuito de relacionar conhecimento à prática. Ao analisar os resultados, é possível verificar que todas as perguntas relacionadas ao exercício do Controle Social estão correlacionadas positivamente com o conhecimento que os discentes têm acerca do tema, porém o coeficiente de correlação mais altos entre os itens foi de 0,433 . Por conseguinte, a correlação entre os itens é fraca, já que nenhum chegou próximo $\mathrm{a}+1$.

Tabela 10: Correlação entre conhecimento e prática do Controle Social

\begin{tabular}{c|c|c}
\hline \multicolumn{2}{c|}{} & $\begin{array}{c}\text { Conhecimento acerca do } \\
\text { Controle Social }\end{array}$ \\
\hline \multirow{3}{*}{$\begin{array}{c}\text { Acesso ao Portal de } \\
\text { Transparência }\end{array}$} & Coeficiente de Correlação & $0,334^{* *}$ \\
\cline { 2 - 3 } & Sig. (2 extremidades) & 0,000 \\
\cline { 2 - 3 } & N & 307 \\
\hline \multirow{2}{*}{$\begin{array}{c}\text { Participar de cursos sobre } \\
\text { Controle Social }\end{array}$} & Coeficiente de Correlação & $0,415^{* *}$ \\
\cline { 2 - 3 } & Sig. (2 extremidades) & 0,000 \\
\cline { 2 - 3 } & N & 307 \\
\hline
\end{tabular}


Tabela 10: Correlação entre conhecimento e prática do Controle Social (continuação)

\begin{tabular}{|c|c|c|}
\hline \multirow{3}{*}{ Denunciar irregularidades } & Coeficiente de Correlação & $0,249 * *$ \\
\hline & Sig. (2 extremidades) & 0,000 \\
\hline & $\mathrm{N}$ & 307 \\
\hline \multirow{3}{*}{ Acompanhar Licitação } & Coeficiente de Correlação & $0,342 * *$ \\
\hline & Sig. (2 extremidades) & 0,000 \\
\hline & $\mathrm{N}$ & 307 \\
\hline \multirow{3}{*}{$\begin{array}{l}\text { Participar de reunião de } \\
\text { Conselhos Municipais }\end{array}$} & Coeficiente de Correlação & $0,200 * *$ \\
\hline & Sig. (2 extremidades) & 0,000 \\
\hline & $\mathrm{N}$ & 307 \\
\hline \multirow{3}{*}{$\begin{array}{l}\text { Solicitar informações de interesse } \\
\text { público }\end{array}$} & Coeficiente de Correlação & $0,189 * *$ \\
\hline & Sig. (2 extremidades) & 001 \\
\hline & $\mathrm{N}$ & 307 \\
\hline \multirow{3}{*}{ Aplicação Geral } & Coeficiente de Correlação &, $433 * *$ \\
\hline & Sig. (2 extremidades) &, 000 \\
\hline & $\mathrm{N}$ & 307 \\
\hline
\end{tabular}

Fonte: Dados da pesquisa (2017).

\section{CONCLUSÃO}

Este estudo teve como objetivo avaliar a relação entre percepção acerca do Controle Social e a efetiva prática do direito, analisando os estudantes de Ciências Contábeis da UFC.

Com uma amostra de 307 alunos, foi possível atingir os objetivos da pesquisa, tanto o principal quanto os específicos. Constatou-se que, em média, os discentes têm um alto nível de percepção $(4,71)$, logo, eles concordam fortemente ou concordam muito fortemente que o Controle Social é fundamental para inibir corrupção, para alinhar as ações dos governantes ao interesse público, assim como a prestação de contas é essencial. Desse modo, o resultado da pesquisa está alinhado com o que postulam Arruda e Teles (2010), Coelho, Cruz e Platt Neto (2011) e Rosa et al. (2016).

Analisando a amostra com relação à prática do Controle Social, pode-se extrair que houve um baixo nível de engajamento dos alunos, em 
média 1,58. Desse modo, no geral, os respondentes ou nunca realizaram ações como acessar o Portal de Transparência e acompanhar uma licitação pública, ou raramente as fazem.

Pode-se, portanto, perceber que por mais que o indivíduo reconheça a importância do Controle Social, a efetiva prática do direito ainda não é exercida de forma plena, pelo contrário, ainda existe uma disparidade se comparada percepção e prática. Vale ressaltar, inclusive, que a amostra foi composta por indivíduos universitários, que têm maior acesso à informação e ao conhecimento e, mesmo diante de um cenário favorável, o nível de participação cidadã foi baixa. Em contrapartida, as variáveis percepção e prática estão relacionadas positivamente a um nível de significância de $1 \%$, ou seja, no geral, aqueles indivíduos que tiveram maior nível de aplicação foram aqueles que atribuíram maior grau de importância ao Controle Social. Dessa forma, pode-se extrair que um dos passos para que o cidadão exerça a participação social é reconhecer a importância desta.

Concernente às barreiras que os discentes encontram para o exercício do Controle Social, a falta de ações do Governo fomentadoras do Controle Social foi o motivo mais recorrente nas respostas dos discentes, ratificando o que foi dito por Di Pietro (1998) e Arruda e Teles (2010), ou seja, que as ações dos governantes não são feitas na extensão suficiente para alavancar de forma significativa a participação do cidadão.

Por fim, é importante ressaltar a relação entre conhecimento e participação cidadã. Por meio do estudo, verificou-se a correlação positiva entre o conhecimento sobre Controle Social e todas as ações correspondentes à prática do mesmo. Além disso, verificou-se que o semestre cursado pelo discente tem relação com o exercício do Controle Social. Dessa forma, é evidente que a educação tem papel fundamental na construção de cidadãos participativos. Esta análise corrobora com a afirmativa de Gadotti (2012) sobre o papel do professor.

Conclui-se, portanto, que a atribuição de importância à participação social como agente ativa no processo político-administrativo do país está 
relacionada ao efetivo exercício do Controle Social, porém, o nível de engajamento do cidadão ainda é muito baixo, mesmo se considerado uma amostra de alunos universitários, posto que o indivíduo esbarra em barreiras culturais, sociais e políticas.

O estudo apresenta algumas limitações, tais como a aplicação somente na UFC e a amostra composta exclusivamente pelos discentes de Contabilidade. Assim, sugere-se que futuros estudos sejam conduzidos com o mesmo enfoque em outras universidades tanto públicas quanto privadas, a fim de fazer comparações entre os resultados. É interessante, ainda, a realização de pesquisa com grupos de diferentes níveis de escolaridade a fim de encontrar um resultado mais próximo à realidade da participação cidadã brasileira.

\section{REFERÊNCIAS}

ALVES, M. V. C. Transparência orçamentária efetiva e internet: um estudo a partir dos portais eletrônicos de orçamento da Câmara dos Deputados e do Senado Federal. Brasília, DF: Câmara dos Deputados, 2009.

ARRAIS, K. M. O exercício do controle social: percepção e atuação dos discentes de instituições do Ensino Médio com relação aos mecanismos de Controle Social. 2016. Monografia (Graduação em Ciências Contábeis) - Departamento de Ciências Contábeis, Universidade Federal do Rio Grande do Norte, Natal, 2016.

ARRUDA, F. A.; TELES, J. S. A importância do controle social na fiscalização dos gastos públicos. Revista Razão Contábil e Finanças, Fortaleza, v. 1, n. 1, 2010. 
BERNARDES, M. B.; SANTOS, P. M.; ROVER, A. J. Ranking das prefeituras da região sul do Brasil: uma avaliação a partir de critérios estabelecidos na Lei de Acesso à Informação. Revista de Administração Pública, Rio de Janeiro, v. 49, n. 3, p. 761-792, 2015.

BRASIL. [Constituição (1988)]. Constituição da República Federativa do Brasil. Brasília, DF: Senado Federal, 1988.

BRASIL. Lei $\mathrm{n}^{\circ} 12.527$, de 18 de novembro de 2011. Regula o acesso a informações previsto no inciso XXXIII do art. $5^{\circ}$, no inciso II do $\S 3^{\circ}$ do art. 37 e no $\S 2^{\circ}$ do art. 216 da Constituição Federal; altera a Lei n ${ }^{\circ} 8.112$, de 11 de dezembro de 1990; revoga a Lei no 11.111, de 5 de maio de 2005, e dispositivos da Lei $\mathrm{n}^{\circ} 8.159$, de 8 de janeiro de 1991; e dá outras providências. Diário Oficial da União: seção 1, Brasília, DF, 18 nov. 2011. Disponível em: https://bityli.com/93bYz. Acesso em: 29 nov. 2017.

BRASIL. Lei ${ }^{\circ}$ 8.666, de 21 de junho de 1993. Regulamenta o art. 37, inciso XXI, da Constituição Federal, institui normas para licitações e contratos da Administração Pública e dá outras providências. Diário Oficial da União: seção 1, Brasília, DF, 26 jun. 1993. Disponível em: https:// bityli.com/B4iH6. Acesso em: 25 nov. 2017.

CARLOS, F. A. Controle social no âmbito municipal: um estudo sobre a utilidade dos relatórios da Controladoria Geral da União (CGU) na percepção dos conselheiros de políticas sociais no Estado de Pernambuco. 2009. Dissertação (Mestrado em Ciências Contábeis) -Universidade Federal de Pernambuco, Recife, 2009.

CÉSAR, J. B. M. A audiência pública como instrumento de efetivação dos direitos sociais. Revista Mestrado em Direito, Brasília, DF, v. 5, n. 2, p. 356-384, 2011. 
COELHO, M. C.; CRUZ, F.; PLATT NETO, O. A. A informação contábil como ferramenta de auxílio no exercício do controle social. Contabilidade Vista \& Revista, Belo Horizonte, v. 22, n. 3, 2011.

CONTROLADORIA GERAL DA UNIÃO. Portal da Transparência do Governo Federal. Disponível em: https://bityli.com/KN5OZ. Acesso em: 29 nov. 2017.

CONTROLADORIA GERAL DA UNIÃO. Cartilha de controle social. Brasília, DF: CGU, 2012. Disponível em: https://bityli.com/6wTMY. Acesso em: 29 nov. 2017.

CORBARI, E. C. Accountability e controle social: desafio à construção da cidadania. Caderno das Escolas de Negócio, 2004.

DI PIETRO, M. S. Z. Direito administrativo. 9. ed. São Paulo: Atlas, 2015.

EVANGELISTA, L. Controle social versus transparência pública: uma questão de cidadania. 2010. Monografia (Especialização em Orçamento Público) - Tribunal de Contas da União, Brasília, DF, 2010.

FIGUEIREDO, V. S.; SANTOS, W. J. L. Transparência e controle social na administração pública. Temas de Administração Pública, São Paulo, v. 8, n. $1,2013$.

GADOTTI, M. Trabalho e educação numa perspectiva emancipatória. In: FÓRUM MUNDIAL DE EDUCAÇÃO PROFISSIONAL TECNOLÓGICA: DEMOCRATIZAÇÃO, EMANCIPAÇÃO E SUSTENTABILIDADE, 2., Florianópolis, 2012. 
GIL, A. C. Como elaborar projetos de pesquisa. São Paulo: Atlas, 2010.

GOMES, E. G. M. Conselhos gestores de políticas públicas: aspectos teóricos sobre o potencial de controle social democrático e eficiente: democracia, controle social e Instituições. Disponível em: https://bityli.com/ DnR13. Acesso em: 2 out. 2020.

HAIGERT, C. G. Controle social e transparência na administração pública municipal de Frederico Westphalen na atualidade. 2012. Monografia (Especialização em Gestão Pública Municipal) - Escola de Administração, Universidade Federal do Rio Grande do Sul, Porto Alegre, 2012.

KAUARK, F.; MANHÃES, F. C.; MEDeIROS, F. C. Metodologia da pesquisa: um guia prático. Itabuna: Via Litterarum, 2010.

LIRA, S. A. Análise de correlação: Abordagem teórica e de construção dos coeficientes com aplicações. 2004. Dissertação (Mestrado em Métodos Numéricos em Engenharia) - Setores de Ciências Exatas e de Tecnologia, Universidade Federal do Paraná, Curitiba. Disponível em: https:// bityli.com/gx52y. Acesso em: 10 nov. 2017.

LOCK, F. N. Participação popular no controle da administração pública: um estudo exploratório. Revista Eletrônica de Contabilidade, Santa Maria, v. 1, p. 122-133, 2004.

MARTINS, P. L.; VÉSPOLI. B. S. O portal da transparência como ferramenta para a cidadania e o desenvolvimento. Revista de Administração da Fatea, São Paulo, v. 6, n. 6, p. 93-102, 2013. 
MEDEIROS, K. R.; CAVALCANTI, P.; TAVARES, A. R. A. W.; SOU$\mathrm{ZA}, \mathrm{W}$. $\mathrm{V}$. Lei de responsabilidade fiscal e as despesas com pessoal da saúde: uma análise da condição dos municípios brasileiros no período de 2004 a 2009. Disponível em: https://bit.ly/3owCwCq. Acesso em: 2 out. 2020.

MILESKI, H. S. Controle social: um aliado ao controle oficial. Revista do Tribunal de Contas do Estado do Rio Grande do Sul, Porto Alegre, v. 22, n. 38, p. 29-44, 2005.

OLIVEIRA, A. G.; PISA, B. J. IGovP: índice de avaliação da governança pública: instrumento de planejamento do Estado e de Controle Social pelo cidadão. Revista de Administração Pública, Rio de Janeiro, v. 49, n. 5, p. 263-1290, 2015.

PIRES, A. K. Gestão pública e desenvolvimento: desafio e perspectivas. Brasília, DF: Ipea, 2011.

RAUSCH, R. B.; SOARES, M. Controle Social na administração pública: a importância da transparência das contas públicas para inibir a corrupção. Revista de Educação e Pesquisa em Contabilidade, Brasília, DF, v. 4, n. 3, p. 23-43, 2010.

ROMERO, H. H.; SANT'ANNA, F. C. C. M. O papel das ouvidorias na comunicação pública do Poder Judiciário. Revista do Serviço Público, Brasília, DF, v. 65, n. 2, p. 185-198, 2014.

ROSA, M. M. et al. A lei de acesso à informação como instrumento de controle social: diagnóstico dos municípios do sul do Brasil à luz do artigo $8^{\circ}$ da lei 12527/2011. Navus: Revista de Gestão e Tecnologia, Florianópolis, v. 6, n. 1, p. 72-87, 2016. 
SABIONI, M. et al. Contextos (in)adequados para o engajamento cidadão no Controle Social. Revista de Administração Pública, Rio de Janeiro, v. 50, n. 3, p. 477-500, 2016.

SALLES, H. M. Gestão democrática e participativa. Florianópolis: UFSC, 2010.

SERRA, R. C. C.; CARNEIRO, R. Controle social e suas interfaces com os controles interno e externo no Brasil contemporâneo. Espacios públicos, México, v. 15, n. 34, p. 43-64, 2012.

SILVA, F. R.; CANÇADO, A. C.; SANTOS, J. C. D. Compreensões acerca do conceito de Controle Social. Desenvolvimento em Questão, Ijuí, v. 15, n. 41, p. 24-58, 2017.

SILVA, I. L. R. Informações no setor público: a percepção dos discentes da Universidade Estadual da Paraíba. 2015. Monografia (Graduação em Ciências Contábeis) - Centro de Ciências Sociais Aplicadas, Universidade Estadual da Paraíba, 2015.

SILVA JUNIOR, S. D.; COSTA, F. J. Mensuração e Escalas de Verificação: uma análise comparativa das Escalas de Likert e Phrase Completion. Revista Brasileira de Pesquisas de Marketing, Opinião e Mídia, São Paulo, v. 15, p. 1-16, 2014. 